University of Nebraska - Lincoln

DigitalCommons@University of Nebraska - Lincoln

Does dynamical downscaling introduce novel information in climate model simulations of precipitation change over a complex topography region?

\author{
George Tselioudis \\ Center for Atmospheric Physics and Climatology of the Academy of Athens, \\ gtselioudis@academyofathens.gr \\ Costas Douvis \\ Center for Atmospheric Physics and Climatology of the Academy of Athens \\ Christos Zerefos \\ Center for Atmospheric Physics and Climatology of the Academy of Athens
}

Follow this and additional works at: https://digitalcommons.unl.edu/nasapub

Tselioudis, George; Douvis, Costas; and Zerefos, Christos, "Does dynamical downscaling introduce novel information in climate model simulations of precipitation change over a complex topography region?" (2011). NASA Publications. 124.

https://digitalcommons.unl.edu/nasapub/124

This Article is brought to you for free and open access by the National Aeronautics and Space Administration at DigitalCommons@University of Nebraska - Lincoln. It has been accepted for inclusion in NASA Publications by an authorized administrator of DigitalCommons@University of Nebraska - Lincoln. 


\title{
Does dynamical downscaling introduce novel information in climate model simulations of precipitation change over a complex topography region?
}

\author{
George Tselioudis, ${ }^{\mathrm{a}, \mathrm{b} *}$ Costas Douvis ${ }^{\mathrm{a}}$ and Christos Zerefos ${ }^{\mathrm{a}}$ \\ ${ }^{a}$ Center for Atmospheric Physics and Climatology of the Academy of Athens, 24 Omirou Str., Athens, 10672, Greece \\ b NASA/GISS-Columbia University, 2880 Broadway, New York, NY 10025, USA
}

\begin{abstract}
Current climate and future climate-warming runs with the RegCM Regional Climate Model (RCM) at 50 and $11 \mathrm{~km}$-resolutions forced by the ECHAM GCM are used to examine whether the increased resolution of the RCM introduces novel information in the precipitation field when the models are run for the mountainous region of the Hellenic peninsula. The model results are inter-compared with the resolution of the RCM output degraded to match that of the GCM, and it is found that in both the present and future climate runs the regional models produce more precipitation than the forcing GCM. At the same time, the RCM runs produce increases in precipitation with climate warming even though they are forced with a GCM that shows no precipitation change in the region. The additional precipitation is mostly concentrated over the mountain ranges, where orographic precipitation formation is expected to be a dominant mechanism. It is found that, when examined at the same resolution, the elevation heights of the GCM are lower than those of the averaged RCM in the areas of the main mountain ranges. It is also found that the majority of the difference in precipitation between the RCM and the GCM can be explained by their difference in topographic height. The study results indicate that, in complex topography regions, GCM predictions of precipitation change with climate warming may be dry biased due to the GCM smoothing of the regional topography. Copyright (c) 2011 Royal Meteorological Society
\end{abstract}

KEY WORDS regional climate models; dynamical downscaling; added value; complex topography; precipitation change

Received 4 September 2009; Revised 15 February 2011; Accepted 5 April 2011

\section{Introduction}

In the last decade, dynamical downscaling with the use of Regional Climate Models (RCMs) has become a convenient and powerful method to document regional climate changes and force regional impact models (e.g. Jones et al., 1995; Jones et al., 1996; Giorgi and Mearns, 1999). The RCM simulations are usually initialized from General Circulation Model (GCM) simulations of the current or future climate. In those types of simulations, one issue that needs to be addressed is the degree to which higher-resolution RCM runs forced by lower resolution GCM output introduce new information that was not present in the output of the forcing GCM, or whether the RCM output simply remaps the already existing information at more detailed scales. To the extent that new information is introduced, one question then is whether and how this information relates to factors like the topographic complexity of the simulated region. In particular, it is crucial to understand whether, in climate change simulations, the use of dynamical downscaling introduces changes with climate that were not inherent in the forcing GCM. The answers to these questions

\footnotetext{
* Correspondence to: George Tselioudis, Center for Atmospheric Physics and Climatology of the Academy of Athens, 24 Omirou Str., Athens, 10672, Greece. E-mail: gtselioudis@ academyofathens.gr
}

may be different depending on the model pair that is analysed, the model parameter that is examined, or the specific geographic region that is simulated in the model experiments.

Previous studies have examined different aspects of the effect of horizontal resolution as well as the effect of the regional topography on nested RCM simulations of climate change. Analysing simulations with the Regional Climate Model (RegCM) of the wider Mediterranean region, Gao et al. (2006a) found large precipitation increases in the upwind side of the major mountain ranges, while on the downwind side, they found smaller increases and even decreases. Hagemann et al. (2008) examined basin-wide precipitation changes with climate over Europe and found differences between the RCM and the forcing GCM that changed sign depending on the season and the simulated region.

The present study aims to examine the differences in precipitation change with climate warming between an RCM and the forcing GCM, for a region with complex topographic features. For that purpose, an RCM is run at two different horizontal resolutions over the mountainous Hellenic peninsula, and the precipitation output is progressively degraded to the resolution of the forcing GCM. The differences between the degraded results and the GCM output are then examined with 
respect to the effects on precipitation of the regional topography and the way it is resolved at the different model scales.

\section{Methodology}

The results of ECHAM5/MPI-OM (Roeckner et al., 2003) GCM at about 200-km resolution were downscaled first to $50 \mathrm{~km}$ and, consequently, to $11 \mathrm{~km}$ using the RegCM (Pal et al., 2007) RCM. The 50-km domain (low resolution) contains a large part of Europe, the Mediterranean, and a part of North Africa, while the 11-km domain (high resolution) contains mainly the area of Greece. For each resolution, two 5-year runs are performed, a history run (1991-1995) and a future climate run based on the IPCC A1B scenario (2091-2095). The GCM results used as Lateral Boundary Conditions for the $50-\mathrm{km}$ runs are available online at the PCMDI database as the 20th century experiment $(20 \mathrm{c} 3 \mathrm{~m})-$ Run 3 and the 720 ppm stabilisation experiment (sresalb) - Run 3. The downscaling results are then analysed with respect to the precipitation field and its changes with climate.

A method is used to upscale higher-resolution parameters to the lower-resolution grids. This is based on averaging the value of all the high-resolution grid points that correspond to each lower-resolution grid point. A higherresolution grid point is considered to correspond to a lower-resolution grid point when the centre of the higherresolution grid point falls within the four corner points of the lower-resolution grid point.

Two monthly gridded observational datasets for precipitation are used to assess the accuracy of the geographical distribution of the results. The Climate Research Unit (CRU) dataset (Mitchell and Jones, 2005) with $0.5^{\circ}$ resolution and the GGDB dataset (Zanis et al., 2008) with $50 \mathrm{~km}$ resolution. The GGDB grid matches exactly the $50-\mathrm{km}$ model domain and it was constructed using monthly precipitation data from 57 stations, most of which are located in Greece. The gridded data were created by performing an interpolation procedure on monthly station observations, specifically a 2-D kriging procedure in association with a back-fitting loop to estimate the elevation component.

\section{Results}

Model simulations of the current climate are examined first to evaluate the ability of the models to simulate regional precipitation. Figure 1 shows the mean precipitation for the 1991-1995 period, simulated by the forcing ECHAM model and the two RegCM runs at $50 \mathrm{~km}$ (low resolution) and $11 \mathrm{~km}$ (high resolution), along with two different observational composites coming from the GGDB and CRU datasets. The two observational datasets are shown at $50 \mathrm{~km}$ resolution. It can
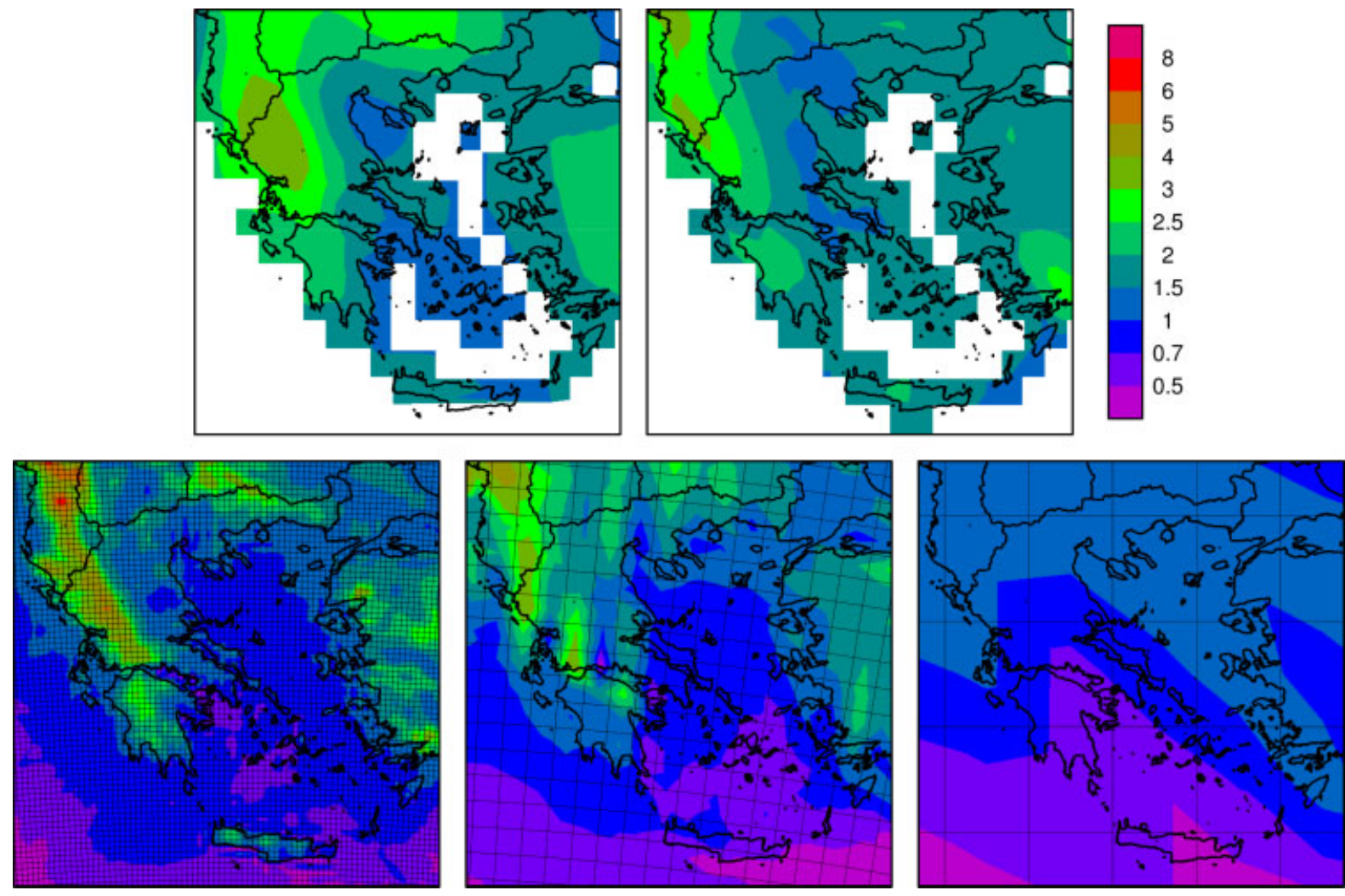

Figure 1. Mean precipitation climatology (1961-1990) from the GGDB (upper left panel) and CRU (upper right) observational datasets at 50-km resolution, and from simulations with the ECHAM GCM (lower right), the RegCM at $50 \mathrm{~km}$ (lower middle), and the RegCM at $11 \mathrm{~km}$ (lower left) in $\mathrm{mm} / \mathrm{day}$. The grid of the respective simulation is presented in each of the lower panels. This figure is available in colour online at wileyonlinelibrary.com/journal/joc 

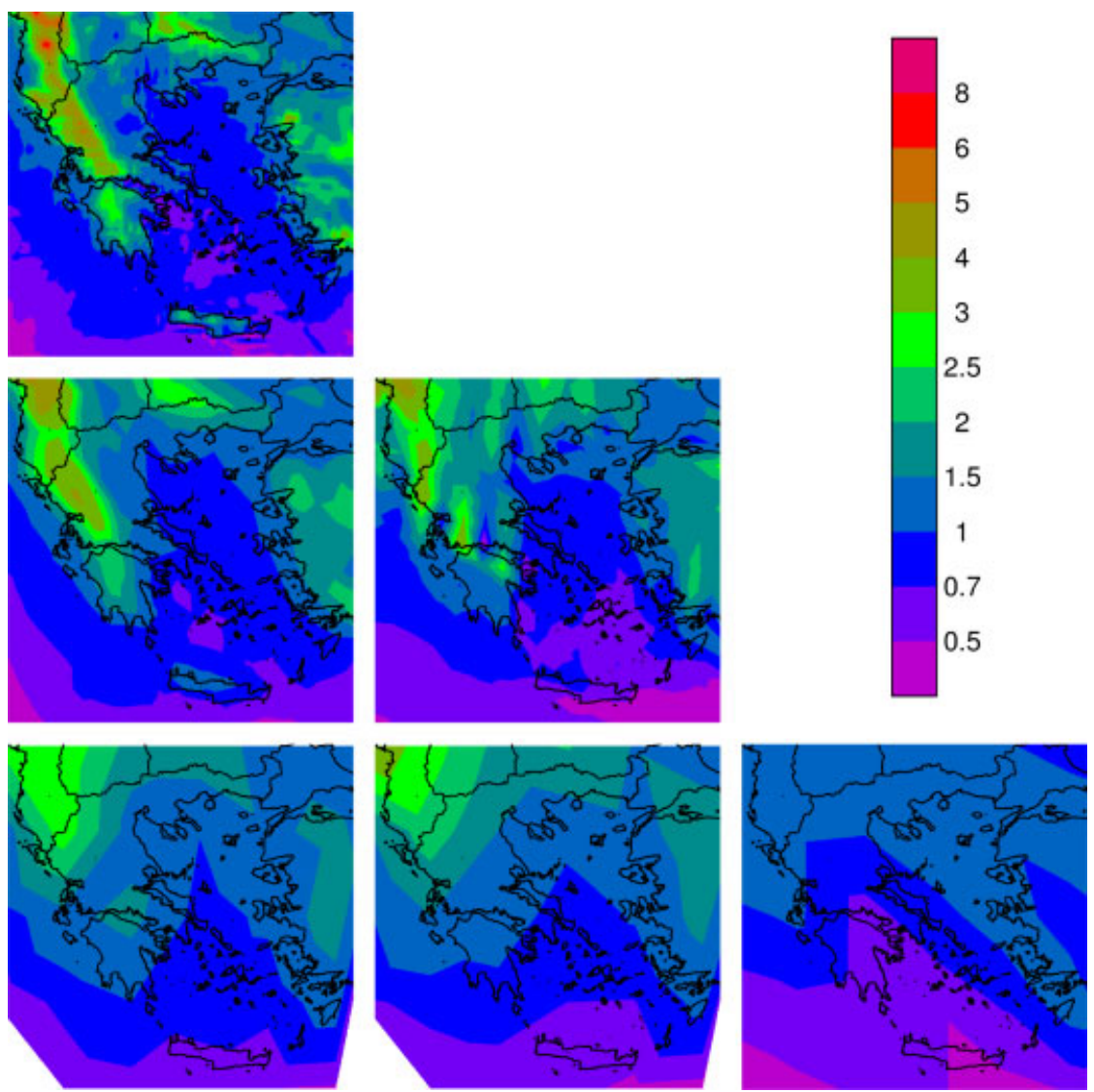

Figure 2. Precipitation simulations for the 1991-1995 period, for the RegCM 11-km run (left-top) degraded to $50 \mathrm{~km}$ (left-middle) and $200 \mathrm{~km}$ (left-bottom), the RegCM 50-km run (middle-top) degraded to $200 \mathrm{~km}$ (middle-bottom), and the the ECHAM run at $200 \mathrm{~km}$ (right) in mm/day. This figure is available in colour online at wileyonlinelibrary.com/journal/joc

be seen that the RegCM runs simulate fairly well the precipitation climatology for the region, with the highresolution run capturing correctly the enhanced precipitation amounts along the mountain ranges that run across the western edge and over the northeastern corner of the Hellenic peninsula. The low-resolution RegCM run also captures well the precipitation maxima in the two mountain regions, but the orientation of the precipitation field is not tilted along with the mountain ranges and the structure of the field exhibits a wave-like pattern not seen in the observations. This may indicate the improper resolution of the mountain effects at $50 \mathrm{~km}$ scales. The ECHAM run shows a precipitation field that does not capture either the precipitation pattern or the amounts found in the observations. It is possible, however, that this is an artifact of the decreased GCM resolution relative to the RCM runs and the observational data.

In order to produce directly comparable results from the different model versions, the resolution of the RCM output for the 1991-1995 run is progressively degraded through linear averaging at the higher resolution scales. Thus, the $11 \mathrm{~km}$ output is degraded to $50-$ and $200-\mathrm{km}$ resolutions, and the $50 \mathrm{~km}$ output is degraded to 200$\mathrm{km}$ resolution. This is shown in Figure 2, where the three left panels include the $11-\mathrm{km}$ run (top) degraded to $50 \mathrm{~km}$ (middle) and $200 \mathrm{~km}$ (bottom), the middle two panels show the $50-\mathrm{km}$ run (top) degraded to $200 \mathrm{~km}$ (bottom), and the third row shows the ECHAM run at $200 \mathrm{~km}$. Comparing the two middle panels, we see similar quantitative estimates, but a pattern that is better aligned along the mountain ranges in the degraded 11$\mathrm{km}$ run than in the 50-km run. Comparing now the three bottom panels we see that the degraded 11 and $50-\mathrm{km}$ runs have small differences, with the high-resolution run showing the large precipitation amounts extending further south in the peninsula, reaching the northern edges of the Peloponnese. The ECHAM run, on the other hand, shows a pattern that, at the same resolution, has no resemblance to the degraded RegCM runs. In addition, the amounts of precipitation falling almost everywhere over land areas in the region are smaller in the GCM output than in the degraded RCM runs.

The precipitation patterns simulated by the three models for the 2091-2095 period are shown in Figure 3, following the same panel pattern that was introduced in Figure 2. The overall precipitation pattern is similar in the warmer climate, with the main precipitation alleys located along the mountain ranges in the west and northeast sides of the peninsula. As far as the differences between the different resolution runs go, similar features to the 1991-1995 run are observed. The 11$\mathrm{km}$ run captures well the precipitation over the orography, while the $50-\mathrm{km}$ run shows again a wave-like, 

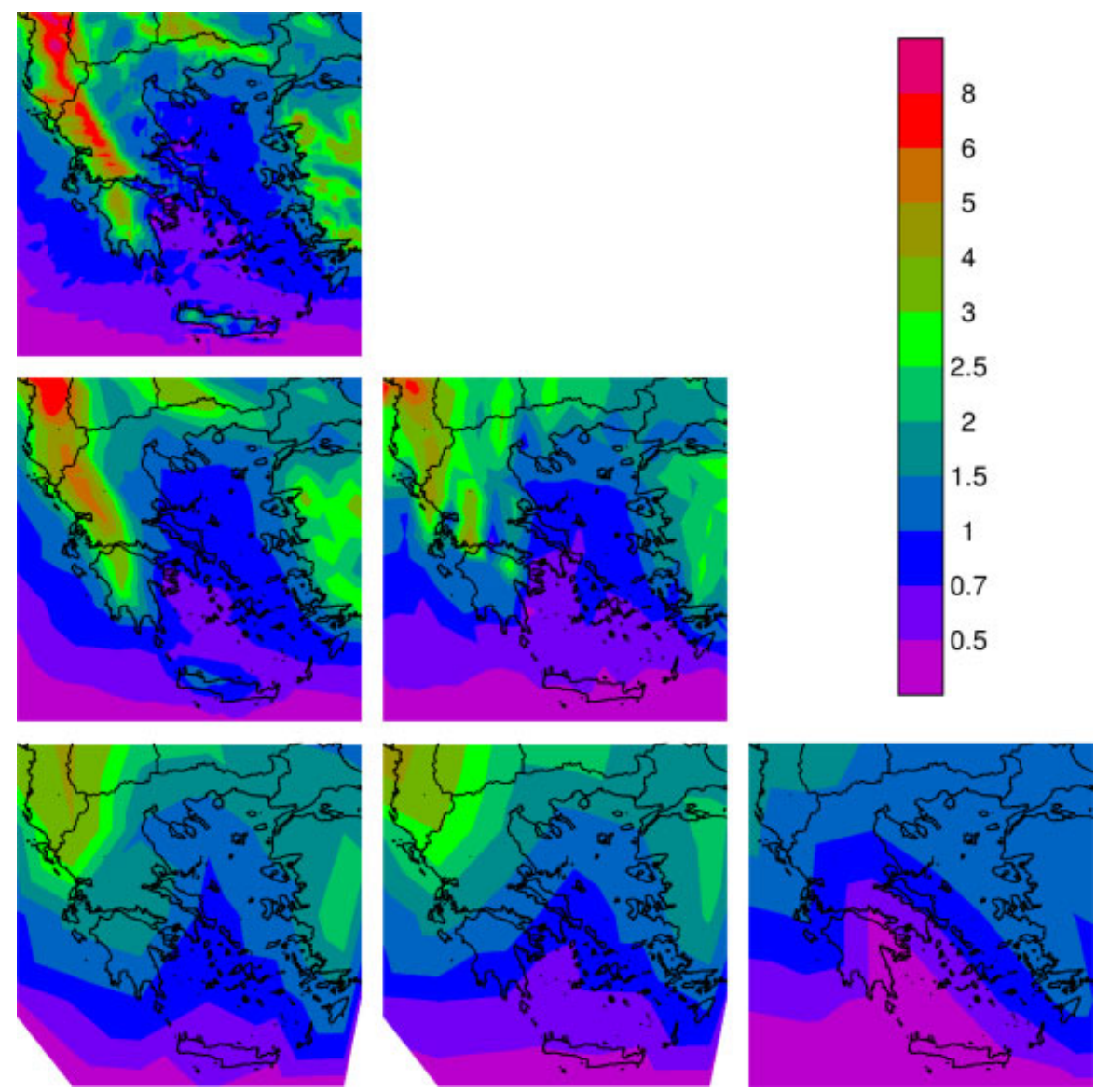

Figure 3. As in Figure 2 for the 2091-2095 period. This figure is available in colour online at wileyonlinelibrary.com/journal/joc

rather than a continuous pattern, over the western mountain range. Also, the $50-\mathrm{km}$ run at the $200-\mathrm{km}$ resolution shows a smaller southern extension of the precipitation maximum than the $11-\mathrm{km}$ run. Finally, the ECHAM run shows a pattern with smaller rain amounts and no pattern similarities with the degraded RCM runs.

The change of precipitation with climate change for the different model versions is pictured in Figure 4, where the precipitation differences between the periods 2091-2095 and 1991-1995 are shown following the panel pattern of the previous two figures. The $11-\mathrm{km}$ RegCM run (left panels) shows precipitation increases with climate warming over the two mountain ranges and near-zero precipitation changes over the rest of the peninsula. The precipitation increase over the western mountain range remains true even as the resolution is degraded to that of the forcing GCM. The $50-\mathrm{km}$ RegCM run (middle panels) shows overall smaller precipitation increases over the northern and western sides of the peninsula than the $11-\mathrm{km}$ run, and this remains true for the versions of the models that are degraded to the GCM resolution. The ECHAM GCM run (right panel), on the other hand, shows near-zero precipitation changes for the whole region of the Hellenic peninsula, and only small precipitation increases to the north of the Greek border. Examining the three bottom panels of Figure 4 , it can be said that the precipitation change patterns of the ECHAM and the 50-km RegCM runs are similar and the differences relate mostly to the latitude where the precipitation change goes from zero to positive. On the other hand, the $11-\mathrm{km}$ RegCM run shows a different precipitation change pattern that includes precipitation increases along the line of the western mountain ranges.

It is important to note here, that the two RCM runs introduce increases in precipitation over the Greek peninsula when forced by a GCM run that simulates near-zero precipitation increase in the same region. The RCM precipitation increases are concentrated over land while both the RCM and GCM simulations show nearzero precipitation changes over Eastern Mediterranean waters. It must be noted here, that precipitation is not one of the forcing ECHAM GCM fields used to initialize the RegCM runs and, thus, is not directly prescribed from the host GCM. It is simulated by the RCM using the temperature, humidity, and wind profiles provided by the GCM at the domain boundaries. Therefore, precipitation changes with climate in the RCM domain are the end result of larger scale dynamic and thermodynamic changes occurring in the GCM which are downscaled and translated to regional precipitation changes by the RCM precipitation scheme. In other words, the RegCM runs are initialized with the same dynamic and thermodynamic conditions that produce the near-zero precipitation increase in the ECHAM GCM. 

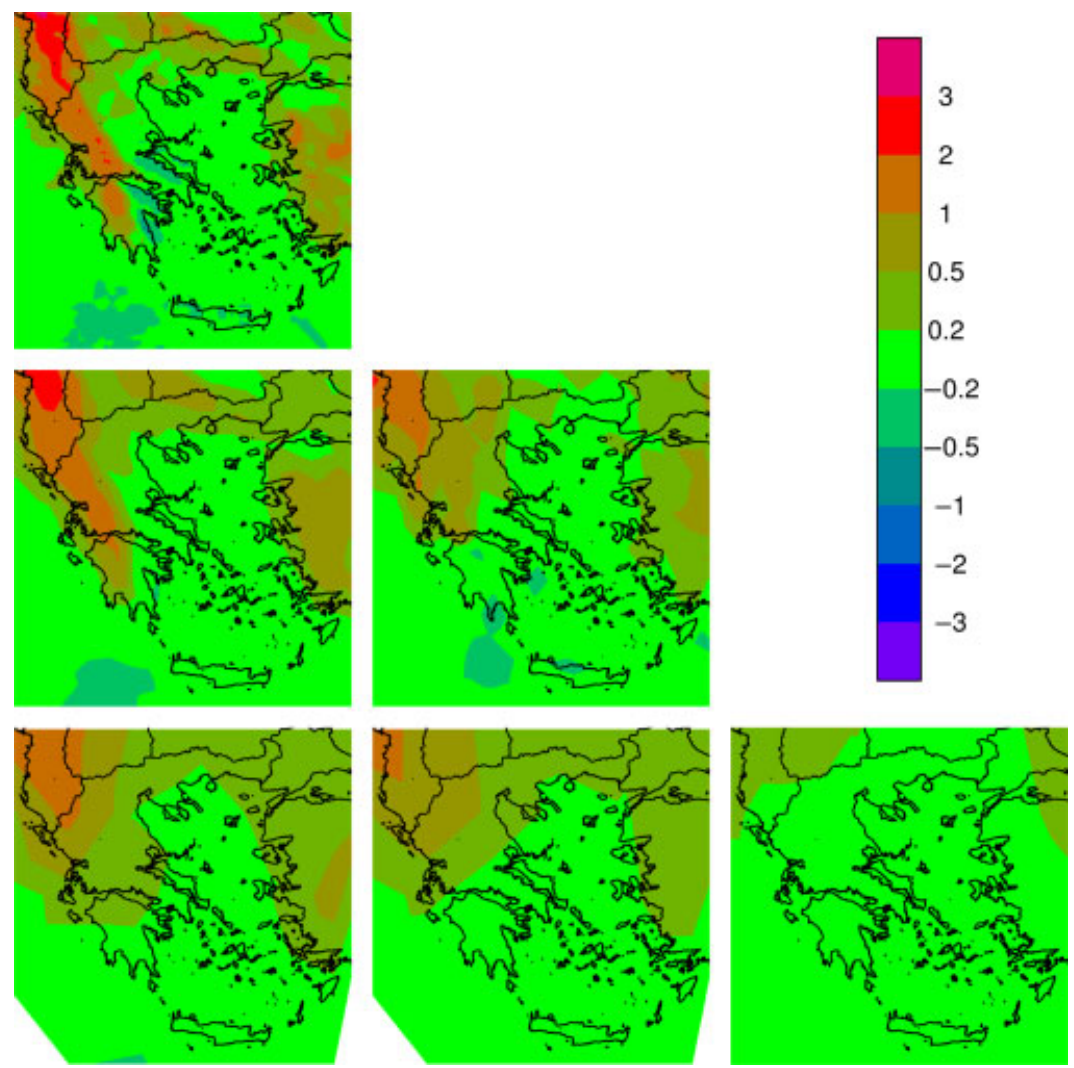

Figure 4. As in Figure 2 for the difference between the 2091-2095 and 1991-1995 periods. This figure is available in colour online at wileyonlinelibrary.com/journal/joc

\section{Discussion}

Current climate and future climate-warming runs with the RegCM Regional Climate Model (RCM) at 50- and $11-\mathrm{km}$ resolutions forced by the ECHAM GCM are used to examine whether the increased resolution of the RCM introduces novel information in the precipitation field when the models are run for the mountainous region of the Hellenic peninsula. The model results are inter-compared with the resolution of the RCM output degraded to match that of the GCM, and it is found that in both the present and future climate runs the regional models produce more precipitation than the forcing GCM. The additional precipitation is mostly concentrated over the mountain ranges, where orographic precipitation formation is expected to be a dominant mechanism. This result can be expected, given that the higher resolution runs resolve better the regional topography and its effects on precipitation. At the same time, however, the RCM runs produce increases in precipitation with climate warming even though they are forced with a GCM that shows no precipitation change in the region. This increased precipitation is also, to some extent, aligned with the regional orography.

The role of orography and its change with resolution is better demonstrated through Figure 5 where the topography of the ECHAM and the 11-km RegCM simulations are presented along with their difference after the upscaling of the RegCM topography to the ECHAM grid. It
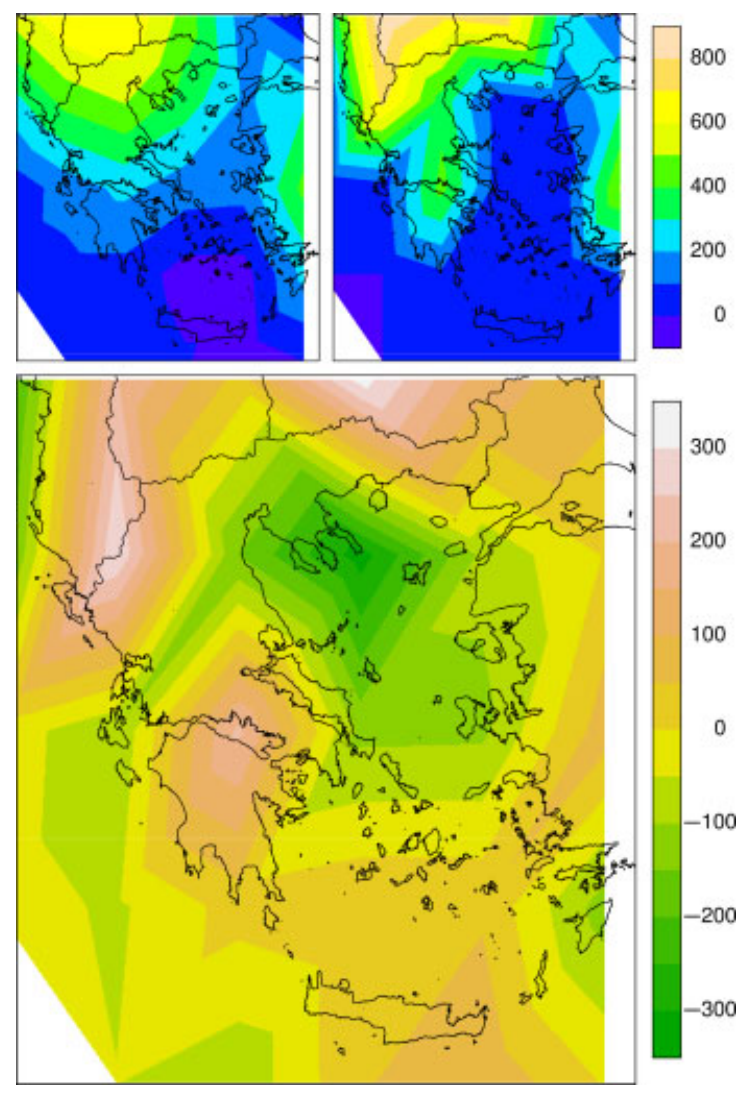

Figure 5. Elevation of the ECHAM GCM (top left) and of the 11-km RegCM simulations degraded to $200 \mathrm{~km}$ (top right) along with their difference (bottom) in meters. This figure is available in colour online at wileyonlinelibrary.com/journal/joc 

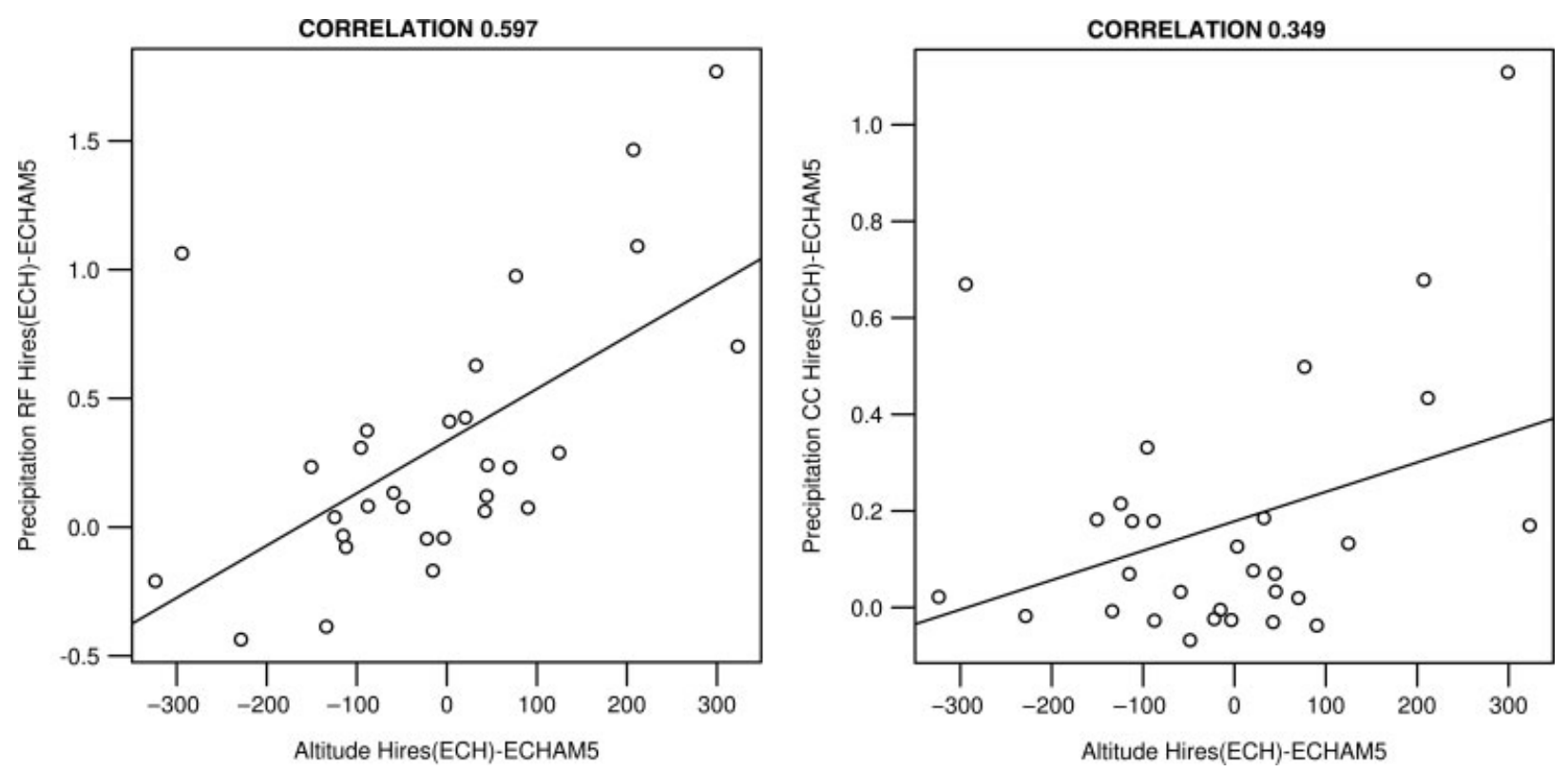

Figure 6. Scatter plots of elevation difference in meters versus precipitation difference in $\mathrm{mm} /$ day between the degraded $11-\mathrm{km}$ RegCM run and the ECHAM run, for the present climate precipitation (left panel) and the precipitation change with climate warming (right panel).

can be seen that even at the same resolution, the elevation heights of the GCM are lower than those of the averaged RCM in the areas of the main mountain ranges. This implies a poor resolution of the regional topography by the GCM at the scale that the model is run. Another issue with the regional topography mapping of the GCM is the negative anomalies over areas covered mostly by sea but also by small peninsulas and islands where the GCM elevation is positive while the RegCM elevation is zero or almost zero even after upscaling to the GCM grid. These positive and negative anomalies make the topography of the GCM in the region much smoother than that of the RCM at the same resolution. Rennsen et al. (2001) indicate that the ECHAM model uses a highly smoothed topography, making the simulation of orographic precipitation a weak point of the model.

In order to relate model precipitation differences to the differences in model topography shown in Figure 5, the scatter plots of elevation difference versus precipitation difference between the degraded 11-km RegCM run and the ECHAM run are plotted in Figure 6 for the present climate precipitation (left panel) and the precipitation change with climate warming (right panel). It can be seen that in the current climate run, the majority of the difference in precipitation between the RCM and the GCM can be explained by their difference in topographic height. The difference in the precipitation change with climate warming, however, is not as strongly correlated to the differences in topography, indicating that those differences may also materialize away from the mountain ranges. Note also that increases in resolution can improve the results by better simulation of the model physics and/or dynamics instead of better representation the topography. Gao et al. (2006b) have shown that the higher resolution can significantly improve the simulation of the east Asia monsoon and that this is not attributed to the improved topography.

This study introduces the possibility that GCM predictions of precipitation changes with climate in regions with mountainous topography may include errors that are caused by the poor resolution of the topography at the GCM space scales. The results indicate that for such complex topography regions GCM predictions of precipitation decreases with climate warming may be exaggerated due to the GCM smoothing of the regional topography. Our results are in accordance with the results of Gao et al. (2006a), who found precipitation changes of different signs between the upwind and downwind sides of the major Mediterranean mountain ranges. In order to generalize those results, however, one needs to run several different combinations of GCM-RCM couples and examine whether the underestimation of the precipitation increases with climate warming found in this study is a general feature or is particular to this GCM-RCM combination. Note that the ECHAM model produces near-zero precipitation change with climate warming in the eastern Mediterranean while most other AR4 models tend to produce precipitation decreases in that region.

The work of Rowell (2006) clearly demonstrates the important role of the forcing GCM in RCM precipitation simulations. A plan for future work on the subject is to examine whether simulations with a suite of GCMRCM combinations will show consistent reductions of the GCM-predicted Eastern Mediterranean precipitation decreases. It is also important to examine whether such consistent precipitation changes will be present is downscaling experiments over regions with flat or gentle topographic features. Comparing GCM and RCM output at the same resolution, this work illustrates that dynamical downscaling of climate change runs can introduce novel 
precipitation change information that is not present in the output of the forcing climate model.

\section{References}

Gao X, Pal JS, Giorgi F. 2006a. Projected changes in mean and extreme precipitation over the Mediterranean region from a high resolution double nested RCM simulation. Geophysical Research Letters 33: DOI:10.1029/2005GL024954.

Gao X, Xu Y, Zhao Z, Pal JS, Giorgi F. 2006b. On the role of resolution and topography in the simulation of East Asia precipitation. Theoretical and Applied Climatology 86: 173-185, DOI:10.1007/s00704-005-0214-4.

Giorgi F, Mearns LO. 1999. Introduction to special section: regional climate modeling revisited. Journal of Geophysical Research 104: 6335-6352.

Hagemann S, Göttel H, Jacob D, Lorenz P, Roeckner E. 2008. Improved regional scale processes reflected in projected hydrological changes over large European catchments. Climate Dynamics DOI: $10.1007 / \mathrm{s} 00382-008-0403-9$.

Jones RG, Murphy JM, Noguer M. 1995. Simulation of climate change over Europe using a nested regional-climate model. I: Assessment of control climate, including sensitivity to location of lateral boundaries. Quarterly Journal of the Royal Meteorological Society 121: $1413-1449$.

Jones RG, Murphy JM, Noguer M. 1996. Simulation of climate change over Europe using a nested regional-climate model. II: Comparison of driving and regional model responses to a doubling of carbon dioxide. Quarterly Journal of the Royal Meteorological Society 123: 265-292.

Mitchell TD, Jones PD. 2005. An improved method of constructing database of monthly climate observations and associated highresolution grids. International Journal of Climatology 25: 693-712, DOI:10.1002/joc.1181.

Pal JS, Giorgi F, Bi X, Elguindi N, Solomon F, Gao X, Rauscher SA, Francisco R, Zakey A, Winter J, Ashfaq M, Syed FS, Bell JL, Diffenbaugh NS, Karmacharya J, Konare A, Martinez D, da Rocha RP, Sloan LC, Steiner AL. 2007. Regional climate modeling for the developing world: The ICTP RegCM3 and RegCNET. Bulletin of the American Meteorological Society 88: 1395-1409.

Rennsen H, Isarin RFB, Jacob D, Podzun R, Vandenberghe J. 2001. Simulation of the Younger Dryas climate in Europe using a regional climate model nested in an AGCM: preliminary results. Global and Planetary Change 30: 41-57.

Roeckner E, Bäuml B, Bonaventura L, Brokopf R, Esch M, Giorgetta M, Hagemann S, Kirchner I, Kornblueh L, Manzini E, Rhodin A, Schlese U, Schulzweida U, Tompkins A. 2003. The Atmospheric General Circulation Model ECHAM5. Part I: Model Description. MPI Report 349. Max Planck Institute for Meteorology: Hamburg, p. 127.

Rowell DP. 2006. A demonstration of the uncertainty in projections of UK climate change resulting from regional model formulation. Climatic Change 79: 243-257.

Zanis P, Kapsomenakis I, Philandras C, Douvis K, Nikolakis D, Kanelopoulou E, Zerefos C, Repapis C. 2008. Analysis of an ensemble of present-day and future regional climate simulations for Greece. International Journal of Climatology DOI:10.1002/joc.1809. 